Session 3280

\title{
Implementing a Satellite Design Experience
}

\author{
Scott A. Starks, Michael E. Austin, Reza Torkzadeh \\ and Bryan Usevitch \\ University of Texas at El Paso
}

\section{Introduction}

This paper describes the planning effort behind the implementation of a satellite design experience for students. This effort has been conducted by faculty at the University of Texas at El Paso (UTEP) working in cooperation with counterparts at California State University, Los Angeles and North Carolina A\&T State University and scientific and technical staff from the Jet Propulsion Laboratory. To date, this activity has been directed toward the goal of securing funding from NASA under the University Explorer (UNEX) Program of the Office of Space Science to support designing, building and launching a satellite dedicated to the taking of solar irradiance measurements.

We envision UTEP students drawn from the Departments of Electrical and Computer Engineering and Information and Decision Sciences as being directly involved in the design of satellite subsystems, in addition to Mission Operations functions. Additionally, students will be directly involved in the archival, distribution and processing of scientific data and data products. Curricular enhancements which are being undertaken at UTEP to accommodate an activity of this importance will be presented. Aspects of project management being employed to coordinate activities among the partnering institutions will also be discussed.

\section{University Explorer Program and Proposed Science Mission}

The objective of NASA's UNEX Program is to conduct space science research where total costs for definition, development, launch service and mission operations and data analysis costs do not exceed $\$ 13$ million. The UNEX Program is one that allows consortia of universities and collaborating organizations to compete for funding to support development of a student-designed satellite. In addition to universities, our consortium includes the Jet Propulsion Laboratory and Space Exploration Engineering. The three university partners serve large numbers of underrepresented minority students. This proposed activity builds upon a previous effort conducted during the summer of 1996 at JPL which brought together students and faculty for a satellite-design experience [1].

As it turns out, the "solar constant" is not constant after all, and there is a 20-year history of measurements from Nimbus and the Active Cavity Radiometer Irradiance Monitor (ACRIM I) spacecraft instrumentation that is heritage to our planned mission. It is the 
objective of our mission to characterize for the first time how the Sun varies through time from the soft X-rays into the infrared.

\section{Plan for Implementing the UNEX Program on the UTEP Campus}

The UTEP activity in the UNEX project will be focused on the following areas:

- Communications Subsystem

- Control and Data Handling Subsystem

- Mission Operations

- Data Archival and Dissemination

Annually, UTEP plans to involve students from eight to ten students from the Departments of Electrical and Computer Engineering and Information and Decision Sciences in meaningful activities relating to these areas. In doing so, the student participants will constitute a pool of highly trained manpower capable of entering the work place at NASA as well as at supporting laboratories and contractors. The area of Mission Operations will present opportunities for the involvement of both engineering and business students. Through this activity, students will be directly involved in the archival of data produced by the proposed instrument as well as in the scientific processing of the data.

The activity plan is to be accomplished by a coordinated effort along three fronts:

- Infrastructure Development: Establishment of a laboratory facility at UTEP to support instruction, design and performance evaluation activities and to serve as a site to support UNEX Mission Operations.

- Subsystems Design and Mission Operations Activities: Conductance of parallel efforts for designing UNEX subsystems and performing UNEX Mission Operations.

- Data Archival and Dissemination: Investigation of mechanisms for the dissemination of scientific data and data products to internal and external constituencies.

\section{Infrastructure Development}

Laboratory development is essential to our plans to create an infrastructure to support UNEX-related design activities. From the onset of the grant period, we plan to place emphasis on the establishment of the UNEX Systems Engineering \& Mission Operations Facility to support instruction and design activities. This facility will house equipment that will be acquired through grant funds and will serve as a venue for enrichment activities.

An important feature of the UNEX Systems Engineering \& Mission Operations Facility will be its capability to support the performance evaluation of space communications systems. The performance evaluation facility will permit the complete simulation of a satellite up link, down link, and inter-satellite channels with the capability of insertion of hardware components to interface with a computer. A powerful computer simulation tool 
will be an integral part of the facility due to the inherent nonlinearity of the satellite's TWT and the large number of parameters involved in the design. Students will perform a combination of paper research and link simulation with all of the components to determine system performance.

Evaluation will include the following components: (1) the modulation and coding scheme to be used; (2) the benefits gained from the use of PCM schemes; (3) the effectiveness of CDMA or a quasi-orthogonal variation of it as a multiple access strategy PM strictly power-limited channels; (4) The link budget analysis; (5) The study of countermeasures to interference in a network of satellites; (6) The study of neural net based equalization techniques, antenna switch combining, and diversity combining to combat ISI caused by multipath.

The UNEX Systems Engineering \& Mission Operations Facility will help train graduate and undergraduate students by enabling them to develop the skills necessary to weigh the advantages and disadvantages of alternative designs. The performance evaluation facility will permit students to conduct meaningful applied research, to gain experience in research methodology, and to become interested in careers relating to satellite communication research.

The UNEX Systems Engineering \& Mission Operations Facility will support UNEX Mission Operations. Here students will be involved in the processing and archival of scientific data obtained from the proposed instrument.

\section{Subsystems Design and Mission Operations Activities}

Design activities associated with the UNEX satellite's Communications Subsystem and its Control and Data Handling Subsystem will be achieved by involving students, primarily seniors and graduate students from the Department of Electrical and Computer Engineering. Students drawn from both the Departments of Information and Decision Sciences and Electrical and Computer Engineering will be involved in supporting UNEX Mission Operations. The proposed implementation utilizes courses and the senior design project laboratory sequence to involve students in design activities. Undergraduate and graduate Electrical and Computer Engineering students will be recruited to serve as members of the UTEP/UNEX design team. Recruitment efforts will concentrate on student's entering their senior year of study. Plans call for these students to enroll in a series of courses that complement the work of the project as follows:

Semester 1 (Fall)

EE 3495: Applied Digital Signal Processing

EE 3495: Special Topics in Electrical Engineering (Communications Enrichment I)

EE 1412: Senior Projects Lab I

Semester II (Spring) 
EE 3441: Communication Systems

EE 3495: Special Topics in Electrical Engineering (Communications Enrichment II)

EE 2412: Senior Projects Lab II

Semester III (Summer)

EE 3488: Digital Communications

EE 3495: Special Topics in Electrical Engineering (Communications Enrichment III)

TABLE 1. Academic Year Course Sequence to Support Subsystem Design Activities

NOTE: The course sequence as shown will be repeated during each year of the grant period.

At the start of each Fall Semester, four to six senior-level and/or graduate electrical and computer engineering students will be selected to participate as members of the UTEP/UNEX design team. During the senior year, selected students will enroll in EE 3495 (Applied Digital Signal Processing), EE 3441 (Communications Theory) and EE 3488 (Digital Communications) as well as the two-semester senior design project sequence. The courses Applied Digital Signal Processing, Communication Theory and Digital Communications courses are intended to provide technical background for students in the theory of analog and digital communication systems. The sequence of Communications Enrichment courses are intended to build upon the topics of analog and digital communications by providing additional, advanced instruction in space communications systems. Through the enrichment class sequence, students will be able to explore facets of communications systems that go well beyond those presented in regular courses. Through the Communications Enrichment sequence, guest speakers will be recruited from NASA and other organizations to supplement lectures given by UTEP faculty.

Students will work with UTEP faculty to formulate a senior design project to support the design of the UNEX Satellite's Communication and Control and Data Handling Subsystems. Students will also be recruited to organize and plan the UNEX Satellite's Mission Operations. The resulting design projects will in turn be completed via the twocourse sequence, Senior Projects Lab I and II. It should be noted that all undergraduate students in the Department of Electrical and Computer Engineering are required to complete a two semester senior design project sequence. In this regard, students investigate an area, formulate a design, implement the design and present it both in an oral and written manner.

Student enrichment will include hands-on work in the UNEX Systems Engineering \& Mission Operations Facility, enrollment in communications enrichment classes, attendance at seminars to promote the awareness of graduate school as well as career opportunities in communications. As part of the team, student participants will be required to enroll in the Communications Enrichment sequence and to contribute to the UNEX program by completing a relevant senior design project or Master's thesis. 
In all cases, the cognizant faculty will work collaboratively with the technical staff at the Jet Propulsion Laboratory and collaborating universities to tailor the research to meet the specific needs of NASA and the UNEX satellite. Visits to the Jet Propulsion Laboratory by the faculty and involved student research assistants are included as a critical part of our plans. We feel that these trips will serve the purpose of focusing the research in a manner as to maximize its benefits to NASA as well as serve as a very important enrichment for students.

\section{Data Archival and Dissemination}

Mission Operations is an area for the involvement of both Information and Decision Sciences and Electrical and Computer Engineering students as part of the UTEP effort in the UNEX project. Combining students from these two disciplines will provide each group with complementary perspectives on data processing within the context of an actual project. For example, Information and Decision Science students regularly take courses such as CIS 3345 (Management Information Systems), CIS 3355 (Business Data Structures), CIS 3430 (Expert Systems and Decision Support Systems), CIS 3470 (Business Data Communications) and CIS 3465 (Data Base Management) as part of their regular course of study at the undergraduate level. The value added that students from Information and Decision Sciences could bring to bear upon the Mission Operations side of the UNEX project is substantial. To facilitate Mission Operations, techniques from artificial intelligence such as expert systems and decision support systems could be developed to assist operators.

We envision that there will be quite a bit of work to do in terms of planning procedures for the storage and archival of data generated by the UNEX satellite. The academic background of students from Information and Decision Sciences especially in the areas of Data Base Management and Data Communications will put them in good stead to contribute to the design of procedures to archive and disseminate data collected from the scientific instrument. Additionally, the ability of these to receive hands-on training in the management and operation of a scientific data processing facility would do much to contribute to their overall education. We envision opportunities for students to develop decision support or expert systems to assist flight operations as well. Procedures and mechanisms for distributing the scientific data to outside parties via the internet or other means would be something interesting to investigate. Faculty from the Computer and Information Systems Department of the College of Business will work with students to develop innovative ways to disseminate scientific data and data products to internal and external constituencies.

The Department of Information and Decision Sciences offers two courses CIS 3496 (Internship in Computer Information Systems) and CIS 3498 (Independent Study in Computer Information Systems) which could be used as vehicles for course credit for students participating in these activities. Additionally, students and faculty from the Department of Information and Decision Sciences will participate with their counterparts 
from the Department of Electrical and Computer Engineering in the Communication Enrichment course sequence.

\section{Growth Potential and Institutional Impact}

Support offered under the UNEX program will enable UTEP's Department of Electrical Engineering to expand its offerings in communications systems engineering. The project will enable the development of laboratories that can be used for research in the areas of telecommunications systems, modulation and coding, and communication network analysis.

The support offered by this project will have a very positive effect on the ability of the institution to offer education in communication systems engineering to its undergraduate students and to attract many of them to pursue advanced degrees. The UNEX Systems Engineering \& Mission Operations Facility will serve as an important venue for involving Information and Decision Sciences students in the hands-on operation of a scientific data processing facility. It is anticipated that design experiences in communications at the senior level will have a beneficial impact on students at a period of time when many are considering whether to attend graduate school or to enter the workplace.

\section{Acknowledgment}

The authors wish to express gratitude to Roger Helizon, Linda Herrell, Alfred Paiz, Kent Tobiska and Donald Young of JPL for their assistance in this project. This work has been supported by JPL under the grant \#96053.

\section{Reference}

1. M.C. Robbins, B. Usevitch and S.A. Starks, "Minority Universities Systems Engineering Program at the University of Texas at El Paso," in NASA University Research Centers Technical Advances in Education, Aeronautics, Space, Autonomy, Earth and Environment, M.Jamshidi (Ed.), pp. 617-621, 1997.

\section{Biographical Information}

SCOTT A. STARKS, Professor of Electrical and Computer Engineering, received a Ph.D. in Electrical Engineering from Rice University in 1978 and a BSEE from the University of Houston in 1973. In addition to his faculty duties, Dr. Starks serves as Director of the Pan American Center for Earth \& Environmental Studies (PACES), a NASA University Research Center on the UTEP campus. 